\title{
Favorable outcome of Covid-19 infection in a pediatric cancer patient receiving an anti-PD-L1 anti-CTLA-4 combination
}

Gabriel Revon-Riviere ${ }^{1}$, Christine Soler ${ }^{2}$, Tina andrianarivony ${ }^{1}$, Sarah Fily ${ }^{1}$, and Nicolas André $^{1}$

${ }^{1}$ Hôpital pour enfants de

${ }^{2}$ Hopital de l'Archet

November 23, 2020

\section{Hosted file}

2020_PBC_Covid ICI AZ.pdf available at https://authorea.com/users/377908/articles/494540favorable-outcome-of-covid-19-infection-in-a-pediatric-cancer-patient-receiving-an-antipd-11-anti-ctla-4-combination 